\title{
Lymphocytes and Melatonin Interaction in COVID-19 and Serotonin Sepsis
}

\author{
Omkar K Choudhari ${ }^{1}$, Anita Rani ${ }^{2}$, Sonam Spalgais ${ }^{3}$, Umesh C Ojha ${ }^{4}$
}

\begin{abstract}
The pandemic of SARS-CoV-2 has affected millions of lives worldwide. Many studies have described the cytokine storm and the subsequent shock behind acute respiratory distress syndrome. Melatonin, a hormone secreted by the pineal gland has excellent anti-inflammatory and immunomodulatory functions. Its role as an adjuvant in the treatment of COVID-19 has been described by many review studies. Serotonin is the intermediate product of melatonin and deficiency of intermediate enzymes causes serotonin surge increasing capillary permeability and shock. Keywords: Cytokines, Inflammation, Melatonin, Serotonin.

Indian Journal of Medical Biochemistry (2020): 10.5005/jp-journals-10054-0145
\end{abstract}

The pandemic of SARS-CoV-2 has affected millions of lives worldwide. The cause of mortality mediated by cytokine storm is documented in many studies. ${ }^{1}$ There is no established specific antiviral treatment as of now and vaccines are under trial. The focus of physicians to counteract the cytokine storm due to unopposed proinflammatory mediator amplification attracted the role of a hormone melatonin. Melatonin is secreted by the pineal gland located in the epithalamus and maintains circadian rhythm. Apart from the mentioned role, melatonin has excellent anti-inflammatory and immunomodulatory properties with the ability to tackle the cytokine storm. ${ }^{2}$ Many reviews have suggested its role from blocking of the cytokines to decrease the oxidative stress and to reduce vessel permeability. ${ }^{3}$

The viral illness predominantly causes lymphocytosis, e.g., Epstein-Barr virus (EBV), infectious mononucleosis (IM), ${ }^{4}$ and even leukemoid reaction is observed in Hantavirus pulmonary syndrome. ${ }^{5}$ The lymphopenia is not certainly a viral infection marker but studies on influenza $A$ suggest that lymphopenia is a poor prognostic marker. ${ }^{6}$ The balanced milieu of bone marrow responds differently to various infections. On the one hand, it responds to infection-causing lymphocytosis enabling to combat viruses and, on the other hand, lymphopenia is considered a poor prognostic marker and was observed in COVID-19 patients in a descriptive Chinese reported ${ }^{7}$ study. The lymphocyte proliferation releases melatonin. ${ }^{8}$ So, in a patient of COVID-19 where melatonin is already deficient with the presence of concomitant lymphopenia results in an increase of severity of the disease. The interplay between lymphocyte and melatonin provides us a novel therapeutic target of this hormone. Melatonin supplements also increase T lymphocyte proliferation indicating its role in $\mathrm{T}$ cell regulation and subsequent immunomodulation. $^{9}$

Deficiency of melatonin due to serotonin $N$-acetyl transferase (SNAT) mutation or downregulation/degradation of receptor or polymorphism of $\mathrm{N}$-acetyl serotonin $\mathrm{O}$-methyl transferase (ASMT) leads to an increased level of serotonin (5-hydroxytryptamine), an intermediate product of melatonin. Serotonin apart from a neurotransmitter also increases endothelial permeability via the Rho kinase pathway. ${ }^{10}$ Increased capillary permeability leads to

\footnotetext{
1,2Department of Biochemistry, Vardhman Mahavir Medical College and Safdarjung Hospital, Delhi, India

${ }^{3}$ Department of Respiratory Medicine, Vallabhbhai Patel Chest Institute, Delhi, India

${ }^{4}$ Department of Respiratory Medicine, Employee State Insurance Hospital, Basaidarapur, Delhi, India

Corresponding Author: Omkar K Choudhari, Department of Biochemistry, Vardhman Mahavir Medical College and Safdarjung Hospital, Delhi, India, Phone: +91 9958166730, e-mail: omkarchoudhari@yahoo.com

How to cite this article: Choudhari OK, Rani A, Spalgais S, et al. Lymphocytes and Melatonin Interaction in COVID-19 and Serotonin Sepsis. Indian J Med Biochem 2020;24(2):81-82.

Source of support: Nil

Conflict of interest: None
}

vascular leak, shock, and acute respiratory distress syndrome (ARDS) indicating its role in sepsis and septic shock.

In COVID-19 patients, ARDS and respiratory failure are some of the most common etiologies in mortality apart from the thromboembolic phenomenon. The polymorphism of ASMT or SNAT or their downregulation induced serotonin sepsis may be responsible for the causation of ARDS. Further studies are required to understand its exact mechanism.

\section{References}

1. Mehta $\mathrm{P}, \mathrm{McAuley} \mathrm{DF}, \mathrm{Brown} \mathrm{M}$, et al. Consider cytokine storm syndrome and immunosuppression. Lancet 2020;395(10229): 1033-1034. DOI: 10.1016/S0140-6736(20)30628-0.

2. Favero G, Franceschetti L, Bonomini F, et al. Melatonin as an anti-inflammatory agent modulating inflammasome activation. 2017;2017:1835195.

3. Zhang R, Wang $X$, Ni L, et al. COVID-19: melatonin as a potential adjuvant treatment. Life Sci 2020;250:117583. DOI: 10.1016/j. Ifs.2020.117583.

4. Pascutti $M$, Erkelens $M$, Nolte M. Impact of viral infections on hematopoiesis: from beneficial to detrimental effects on bone marrow output. Front Immunol 2016;7:364.

(0) The Author(s). 2020 Open Access This article is distributed under the terms of the Creative Commons Attribution 4.0 International License (https://creativecommons. org/licenses/by-nc/4.0/), which permits unrestricted use, distribution, and non-commercial reproduction in any medium, provided you give appropriate credit to the original author(s) and the source, provide a link to the Creative Commons license, and indicate if changes were made. The Creative Commons Public Domain Dedication waiver (http://creativecommons.org/publicdomain/zero/1.0/) applies to the data made available in this article, unless otherwise stated. 
5. Duchin JS, Koster FT, Peters CJ, et al. Hantavirus pulmonary syndrome: a clinical description of 17 patients with a newly recognized disease. The hantavirus study group. N Engl J Med 1994;330(14):949-955. DOI: 10.1056/NEJM199404073301401.

6. Cunha BA, McDermott BP, Mohan SS. The diagnostic and prognostic significance of relative lymphopenia in adult patients with influenza A. Am J Med 2005;118(11):1307-1309. DOI: 10.1016/j. amjmed.2005.06.018.

7. Tan $L$, Wang $Q$, Zhang $D$, et al. Lymphopenia predicts disease severity of COVID-19: a descriptive and predictive study. Sig Transduct Target Ther 2020;5(1):33. DOI: 10.1038/s41392-020-0148-4.
8. Miller SC, Pandi PSR, Esquifino Al, et al. The role of melatonin in immune-enhancement: potential application in cancer. Int J Exp Pathol 2006;87(2):81-87. DOI: 10.1111/j.0959-9673.2006. 00474.x.

9. Luo J, Zhang Z, Sun $\mathrm{H}$, et al. Effect of melatonin on T/B cell activation and immune regulation in pinealectomy mice. Life Sci 2020;242:11719. DOI: 10.1016/j.Ifs.2019.117191.

10. Tanaka T, Mori M, Sekino M, et al. Serotonin and vascular permeability (serotonin beyond the brain) - analysis of serotonin in sepsis and ARDS. Respirology 2018;23:53. DOI: 10.1111/resp. 13419_125. 